dating approximately from 4,000 B.c. Among a number of other indications of affiliation is the Libyan sheath, shown on figures at Fedjet el Khaïl and Kharrouba, which links with the Amratians, the predecessors of the Gerzeans, dating from $5,000-4,000$ B.c., while an individual at Kharrouba holds a boomerang, which appears also among the Badarians of predynastic Egypt. Finally, the polished axes, the biface arrow-heads, and the harpoons and the fish-hooks of bone, which in North Africa extend as far as Mauretania, also appear in the earliest neolithic civilization of Egypt, the Tasian of the Fayum and Merimde, while the arrow-heads with transverse cuttingedge are found in the Amratian culture.

The neolithic with Capsian tradition of Oran is thus seen to comprise a number of features which derive from Egypt, but are found there as elements in cultures which succeed one another in a period extending from 6,000 to 4,000 B.C. In the Sahara these features appear more or less contemporaneously, as is shown not only by surface finds, but also on stratified sites. Hence the impression left by this neolithic culture of Capsian tradition is that it has been built up on a Capsian foundation by a succession of borrowings from the neolithic cultures of Egypt. It is a colonial culture, and like all such, is affected by a time-lag. Thus, for example, the head of a ruminant surmounted by a disk first appears in Egypt in the Amratian culture. The same figure, accompanied by bovides and ovides, appears in North Africa, but probably dating from the Middle Kingdom. Another example of the same kind is the painted representations of vehicles, which have been attributed variously to the Garamantes and other sources. The simplest explanation is that these paintings are the work of natives who had been in contact with Egypt under the New Empire, but certainly after the introduction of the horse and chariot into Egypt by the Hyksos. This would give a dating for the culture associated with these paintings, or of those representing the horse alone, such as that at Oued Chreaa, of $1,500-1,000$ B.c.

While $3,500-4,000$ B.c. would thus represent the extreme upward limit of dating for the neolithic culture of Capsian tradition, the gap which exists between this culture and the Mousterian or Aterian in southern Oran and probably throughout the whole of the Sahara, leads to the conclusion that no naturalistic engraving in the whole of this region is older than the neolithicoCapsian culture which is found in association with this North African school of art.

\title{
Natural Colour Eclipse Photography
}

$\mathrm{T}$ HE first natural colour photograph of a total eclipse of the sun ever reproduced appears in the February issue of the National Geographic Magazine. The original photographs were taken on June 19, 1936, at Ak Bulak in Siberia, by Irvine C. Gardner, leader of the National Geographic Society and U.S. National Bureau of Standards Joint Eclipse Expedition.

Dr. Gardner, in his very interesting article describing the general circumstances of the observations, states that six exposures on Dufay colour plates (of $1,2,4,8,16$ and 8 seconds respectively) were made with a specially designed lens of 9 inches aperture and 19-feet focal length. The camera was fixed, being pointed directly at the eclipsed sun, and the plate holder moved to compensate for the solar motion. The solar image had a diameter of almost two inches. One of the photographs is reproduced in colour among the illustrations to the article.

It is perhaps scarcely fair to judge the original photographs by the reproduction, though there is no mention in the text of any differences between the original and the reproduction. The detail shown is, as one would expect, less than in the usual 'black and white' pictures, but all the main structure of the corona is visible, and the image extends to about a solar radius from the limb of the sun. The sky background is reproduced as a brownish-grey, rather than indigo, and the corona itself is distinctly pink, though it is pearly white to bluish to the eye. The prominences show whitish to blue, and this seems to be nearer the truth than the common idea of a vivid scarlet.

The precise object of these photographs is not stated in the article, which is a popular account, but despite these defects as pictures corresponding to direct eye observation, these pioneer attempts at colour photography of eclipses are of enormous interest, for to the astronomers it matters little whether the photograph looks like the original. The important thing is whether there exists a one to one correspondence between the spectral composition of the radiation reaching us from the corona and prominences and the radiation transmitted by the photograph ; or, to be more exact, can the spectral intensity curve of the source be deduced from the spectral absorption curve of the photograph? 
Of course, such 'mosaic' processes as the Dufay colour, and nearly all natural colour processes, do not seek such a correspondence between source and image, but only that the image should closely resemble the source to the eye. As a given hue to the eye may be produced by more than one combination of homogeneous radiation, it does not follow that a colour photograph satisfactory to the eye would be equally satisfactory to the spectroscope, and so far no commercial process satisfies this latter test. But at least a 'mosaic' colour photograph can have the same sort of value that a set of ordinary photographs taken through filters has, and represents a coarse spectro-photometric survey.
Dr. Gardner in his article does not state explicitly whether any steps were taken to make photometric measurements, but by implication something of the sort was contemplated. If it should prove practicable - and these first results of Dr. Gardner's hold high promise-to conduct even rather rough eclipse spectrophotometry in this fashion, then a new technique of great value will be at our disposal. It is too early to express any opinion on the possibilities of this method, but Dr. Gardner is to be congratulated not only on his luck in obtaining clear skies at Ak Bulak, but also on his enterprise and his technical skill in securing these photographs.

\section{Obituary Notices}

\section{Dr. W. Maldwyn Davies}

$\mathrm{B}^{\mathrm{Y}}$ the sudden and tragic death on February 17 of Dr. W. Maldwyn Davies of Bangor at the age of thirty-four years, entomology, and notably economic entomology, has suffered a grievous loss. Dr. Davies graduated with first-class honours at the University College of North Wales, Bangor, in 1925, and after two years at the Rothamsted Experimental Station he returned to the College in 1927 as adviser in agricultural zoology for North Wales, an appointment which comprised not only duties of a purely advisory character but also to no small extent investigation and research. For this post Davies, with his intimate knowledge of Welsh farmers and Welsh farming, was exceptionally well qualified, as evidenced by his work in connexion with the warble fly, in which science and practice were so happily combined.

Even more outstanding, however, was the research work that Davies was able to carry out in the brief period of ten years. Most notable perhaps was his contribution to our knowledge of the ecology of the aphis Myzus persicce and its relationship to the spread of the virus diseases (mainly leaf-roll) of the potato. Starting from the discovery made by his colleagues, especially Dr. T. Whitehead, that in certain parts of North Wales potatocs could be grown from year to year without the introduction of fresh seed and without appreciable increase in the incidence of virus disease, Davies began a study of the aphis vectors of these diseases. By investigating the population of the aphides in the field, he was able to show that there is a significant difference in the numbers of aphides on farms where healthy seed potatoes could be grown and on those where they could not, a difference which in itself explained the varying incidence of virus disease. At the same time, the important discovery was made that the source of infestation each year was not overwintered oggs on various species of Rosacer, but aphides in the apterous stage overwintering on Brassicas, particularly Savoys, and it was concluded that winter Crucifers provide the main source of $M$. persicce in spring.

The next step was to discover the factors that control the aphis population, and by a combination of laboratory and field work, Davies was able to show that the numbers of aphides in any district depend in part on the proximity of winter host plants but even more on the climatic conditions during tho periods of migration. It was found that the aphides are unable to fly when the atmospheric humidity exceeds a certain maximum, owing to the effect of moisture on the wing membranes. It was also found that strong winds, instead of favouring migration, cause the insects to remain in situ on the host-plant. The potato-growing areas of North Wales could thus be differentiated on purely meteorological grounds into districts in which the transmission of virus disease would be facilitated by the presence of abundant vectors and those where it would not.

The last stage of the investigation, to establish whether the facts that held good in North Wales were also true of Great Britain as a whole, was already under way, and a visit to Scotland last year was to have been followed this year by a trip to Devon and Cornwall. This conclusion of the work must now be left to others, but Davies's contribution will remain a model of what such an investigation should be, and it is likely to rank as classic in its particular sphere.

Davies was not concerned only with the insects that attack plants, and his work upon tho pests of farm animals, notably upon the sheep maggot flies, was of little less importance. At the instance of the Agricultural Research Council, he had recently had the co-operation of a biochemist (Dr. R. P. Hobson) in an investigation of these latter pests - a collaboration that had already produced valuable results and held out great promise of further success. 